\title{
GBEP
}

\section{El Contrato Social de la pax capitalis: la necesidad de un juicio educativo en red}

Carlos Riádigos Mosquera

http://dx.doi.org/10.1590/S2176-6681/335312409

\section{Resumen}

El Contrato Social es el concepto filosófico empleado durante siglos para encuadrar las relaciones de convivencia entre los seres humanos en diferentes sociedades, una vez "superado" el prepolítico Estado de Naturaleza. En los sistemas capitalistas contemporáneos, estamos reproduciendo sociedades asimétricas en relación al poder a través de contratos sociales que habitualmente abrigan un estado de paz ficticia y forzada, mediante la naturalización de las desigualdades y la imposición de los dogmas del capital. Esa es la pax capitalis, similar a la pax romana que el imperio imponía en sus territorios a todos los pueblos conquistados. Mediante esta reflexión teórica, apoyada en análisis documental de autores de la teoría contractual, se pretende contribuir a mostrar caminos que, desde la educación, puedan dar respuesta a esta forma hegemónica de concebir la sociedad como un contrato entre partes desiguales y además diferentes. Las conclusiones obtenidas del trabajo apuntan que esa respuesta tiene que pasar por una forma de entender la educación orientada a la democracia 
participativa y por lo tanto a la justicia social, con la utilización de la estructuración en red como vehículo que dé coherencia interna al sistema, además de funcionalidad práctica para el siglo XXI.

Palabras clave: contrato social; estado de naturaleza; capitalismo; paz; educación en red; justicia.

\section{Abstract \\ The Social Contract of pax capitalis: the need for an educational judgment in network}

The Social Contract has been a philosophical concept used for centuries to frame the relationships among people in different societies, once the prepolitical State of Nature is "overcome". In contemporary capitalist systems, we are reproducing asymmetrical societies in relation to power through social contracts that usually harbor a state of fictitious and forced peace, through the naturalization of inequalities and the imposition of capital dogmas. That is the pax capitalis, similar to the pax romana imposed inside the empire to all the conquered peoples. Using this theoretical reflection, supported by documentary analysis of authors of the contract theory, this study intends to show paths that, through education, can respond to this hegemonic way of thinking society as a contract between unequal and, also, different parts. The conclusions of the study show that this response has to go through a form of understanding education oriented to the participatory democracy and, therefore, to social justice, with the use of a network structure as a vehicle that gives internal consistency to the system, as well as practical functionality for the XXI century.

Keywords: social contract; state of nature; capitalism; peace; network education; justice.

\section{Resumo \\ o Contrato Social da pax capitalis: a necessidade de juízo educativo em rede}

O Contrato Social é o conceito filosófico empregado, durante séculos, para enquadrar as relações de convivência entre os seres humanos em diferentes sociedades, quando "superada" a situação pré-política do Estado de Natureza. Nos sistemas capitalistas contemporâneos, estamos reproduzindo sociedades assimétricas em relação ao poder, por meio de contratos sociais que habitualmente abrigam um estado de paz fictícia 
e forçada, mediante a naturalização das desigualdades e a imposição de dogmas do capital. Essa é a pax capitalis, similar à pax romana que o império impunha em seus territórios a todos os povos conquistados. Mediante essa reflexão teórica, apoiada em análises documentais dos autores da teoria contratual, pretende-se contribuir para a demonstração de caminhos que, a partir da educação, possam responder a essa forma hegemônica de conceber a sociedade como um contrato entre partes desiguais e também diferentes. As conclusões obtidas pelo trabalho demonstram que essa resposta tem que passar por uma forma de entender a educação orientada para a democracia participativa e, portanto, para a justiça social, de modo a utilizar a estruturação em rede como veículo que dá coerência interna ao sistema, além de funcionalidade prática para o século XXI.

Palavras-chave: contrato social, estado de natureza, capitalismo, paz, educação em rede, justiça.

\section{Un Estado de Naturaleza socialmente impuesto}

El concepto de Estado de Naturaleza hace referencia a aquel en el que rige la ley natural, en el que la fuerza y el deseo de cada persona dirigen todas las conductas. No existen contratos ni límites legales que regulen las relaciones entre los seres humanos, por lo que, acudiendo a la teoría clásica, es un estado prepolítico. Es por esta ausencia que la tradición filosófica marca dos pautas claras: en primer lugar, los seres humanos sin leyes sociales estarían predestinados al conflicto y a la guerra, y en segundo, serían esas leyes las que solucionarían esos problemas del Estado de Naturaleza.

[...] En una condición así, no hay lugar para el trabajo, ya que el fruto del mismo se presenta como incierto; y consecuentemente no hay cultivo de la tierra; no hay navegación... no hay letras; no hay sociedad. Y, lo peor de todo, hay un miedo constante y un peligro constante de perecer de muerte violenta. Y la vida del hombre es solitaria, pobre, desagradable, brutal y corta. (Hobbes, 1984, p. 107).

Con esa postura, Hobbes defiende que en Estado de Naturaleza todo es caos para la existencia humana. Además de haber confrontación, no hay para él posibilidad alguna de avanzar si no es en la vida en sociedad, con unas normas que le den forma y un poder coercitivo que mantenga la situación. El vínculo social está presente por los beneficios reportados, no proviene de un imperativo natural, $y$ vivir en sociedad no es suficiente en sí mismo para eliminar el instinto del ser humano tendente al conflicto.

Por su parte, Locke (1995) consideraba que el Estado de Naturaleza es la condición en la cual no hay autoridad gubernamental ni propiedad personal. Señala entre las deficiencias a corregir del Estado de Naturaleza, la tendencia de los seres humanos a no respetar la propiedad de otras 
personas y a castigar esas transgresiones con más severidad que la que la ley natural permite. Para el autor, el estado natural del ser humano es de libertad e igualdad, y el hombre debe conservarse a sí mismo en virtud de la ley fundamental de naturaleza, primando la defensa de los inocentes (Locke, 1995). Esta postura muestra ya cierta tendencia a preservar la vida de determinadas personas no beligerantes o inocentes, lo que lo distingue de Hobbes, y que significó un paso importante en la teoría contractual hacia caminos más inclusivos dentro de la misma.

Kant (2006) también entendía que la vida en Estado de Naturaleza es globalmente negativa para el ser humano, pudiendo desarrollar mejor sus potencialidades cuando comparte ésta con más personas. Señaló que fuera de la asociación civil no hay aprovechamiento de la condición humana. También en esa línea, Rousseau (1993) defendía la postura de que no hay derechos naturales de personas sobre otras, ya que parte de la idea de que todos los "hombres" nacen libres e iguales por naturaleza. Son así las convenciones entre personas iguales y libres las que decidirán quién tendrá autoridad legítima.

Pero la contemporaneidad ha venido a romper con esta separación dicotómica entre Estado de Naturaleza y Contrato Social en relación a la paz social y el caos. Así, autores como Santos (2007) argumentan que esa distinción supuestamente clara entre ambos no lo es tanto. Los enormes desequilibrios sociales actuales en el marco de los contratos sociales demuestran un panorama en el que, muchos seres humanos quedan desprotegidos frente a la violencia, que ya no es directa y personal, es sistémica y difusa, a lo que el autor denomina fascismo social, y que es un falseamiento del contrato porque nos lleva de vuelta a un estado natural (entendido como salvaje), presocial.

Es posible pensar en comunidades, a las que el pensamiento hegemónico bien podría atribuirles el "Estado de Naturaleza”, es decir, sin un control firme y a través de leyes por parte de una figura central de poder, como el Estado. Algunas de esas comunidades, gracias a sencillas normas de convivencia, funcionan de forma autónoma, fluida y relativamente satisfactoria, al mismo tiempo que otras sociedades mucho más complejas y clásicas, y que fijan sus ejes políticos en la teoría del contrato, tienen serios problemas de legitimidad democrática en relación a respetar sus propias leyes. En cuanto al primer caso, y basándonos en las interpretaciones contractualistas de autores como Sen (2010) y Nussbaum (2006), podemos ver, por ejemplo, cómo movimientos sociales como el brasileño de 2013 o el español de 2011, o experiencias políticas ciudadanas como las de Porto Alegre (Brasil), basan fuertemente su convivencia interna en acuerdos prepolíticos, en el sentido de que están basados en lo que nos debemos unas/os a otras/os por pertenecer a la misma especie, muy en sintonía con la Declaración de los Derechos Humanos. Al mismo tiempo, y en relación al segundo caso, estados autodenominados como "civilizados" por tener una teoría del contrato temporalmente asentada, como es el caso de diferentes 
países europeos, incumplen sistemáticamente requisitos indispensables para cohabitar en paz internamente, en relación a la justa distribución de recursos, por ejemplo.

Lo anterior es perfectamente aplicable a diferentes sistemas educativos que nos encontramos por el mundo. Muchos de ellos están fuertemente estandarizados y violentados por evaluaciones competitivas, debido a la coacción de normas estatales e incluso internacionales, como sucede con la OCDE (Organización para la Cooperación y el Desarrollo Económico) y su sistema de evaluación educativa PISA (Program for International Student Assessment) (Torres Santomé, 2011). Se suma a la estandarización una creciente reglamentación interna, a la que no acompaña el crecimiento en derechos distributivos o participativos, por ejemplo, y a pesar de la cual continúa siendo difícil facilitar por esta vía a sus sociedades (las educativas) ambientes de convivencia justos y pacíficos (Castro García, 2006). Son ambientes educativos que están volviendo a un estado de pseudonaturaleza desde la perspectiva de la inevitable violencia fuera de lo social, tal y como defendía Hobbes.

Y es que la historia nos muestra que la justicia social siempre estuvo más ausente que presente en diferentes sociedades, aunque es cierto que hubo importantes avances con el paso del tiempo. Justicia, entendida en este punto, en relación a la capacidad de hacer que todas las personas afectadas por el contrato fueran también firmantes del mismo, en el sentido de disfrutar de todos los derechos y posibilidades que su época les otorgaba para ser protagonistas activos en la búsqueda de su felicidad. El momento actual, marcado por la trayectoria capitalista que viajó de la mano con la modernidad, es especialmente grave en este sentido, ya que a pesar de las grandes contribuciones modernas a la sociedad, como el gran desarrollo de la tecnología y los medios de producción, estos no han sido utilizados para satisfacer las necesidades de los seres humanos a gran escala. Estamos en un momento de superpoblación planetaria, pero al mismo tiempo nunca tuvimos como ahora tantas y tan buenas herramientas para cubrir nuestras demandas, y sin embargo el mundo se polariza en cuanto a recursos. Un ejemplo claro en este sentido es todo lo que sucede en buena parte de Europa desde el año 2008, comienzo de la llamada "crisis" económica, la mayor desde la Gran Depresión de 1929, y que es sólo una continuación de las recetas neoliberales antes aplicadas en África y América Latina. Por ejemplo, la cantidad de dinero (cuatro billones y medio de euros) entregados a la banca de diferentes países en el mundo para solucionar los problemas financieros creados por sus propias prácticas especulativas, y permitidas por los gobiernos de los distintos países afectados, sería suficiente para paliar el hambre en el mundo 92 veces (Oliveres, 2012), hambre que se lleva 60.000 vidas cada día en el planeta. Aquí no es posible hablar ni siquiera de que se violenta el trabajo, la tierra o la vivienda, siguiendo a Hobbes, porque es la vida la que es robada.

En este sentido, Locke (1995) mantenía que el hombre debe conservarse a sí mismo en virtud de la ley fundamental de naturaleza, primando la defensa de los inocentes. Pero los países que sufrieron las mayores 
agresiones coloniales, fundamentalmente en África y América del Sur, fueron saqueados durante siglos y aún padecen, en la actualidad, de políticas externas o internas que afectan muy negativamente a su ciudadanía. La población de esos países no estaba "presente" en el momento de la "firma". Entonces, ¿quién "firmó" por ella?. En un momento histórico en que tenemos información, capacidades y materiales más que suficientes para que todas las personas se puedan desarrollar en plenitud, no poder hacerlo por causa de las asimetrías contractuales es un error sistémico que anula cualquier base de paz democrática.

\section{El capital como falsa firma de los contratos sociales}

El Contrato Social, como acuerdo (explícito o implícito, impuesto o acordado) pactado por los miembros de un grupo, lleva asociado, entre otras cosas, que estos renuncien a parte de su libertad personal, la cual proviene del Estado de Naturaleza, cediendo, por ejemplo, el uso privado de la fuerza ante una autoridad, para así obtener paz, seguridad y expectativas de beneficio mutuo. Ese pacto o contrato otorga a la ciudadanía legítimos deberes y derechos que pasan a ser regulados por el órgano competente, mediante distintas constituciones, convenciones y leyes.

Es importante tener en cuenta que, cuando hablamos de contratos sociales, es necesario saber si son sólo una construcción filosófica o también una realidad social. Hume (1988), por ejemplo, ridiculizó la idea de que sean reales y cuestionó el valor que los acuerdos imaginarios puedan tener para explicar las obligaciones políticas. La mayoría de autoras/es del contrato admiten que casi nunca se da un acto explícito de acuerdo en una comunidad, pero todo acuerdo está implícito cuando los miembros de la sociedad participan en determinados actos por los que dan su consentimiento tácito al régimen de gobierno, y por lo que renuncian a ciertas libertades para cohabitar en armonía.

Dentro del contractualismo, la corriente filosófica del utilitarismo fue decisiva en las configuraciones de las sociedades en los últimos siglos. Filósofos como Hume, Smith, Bentham y Stuart Mill fueron firmes defensores de esta teoría, basada en el principio de que la justicia se consigue cuando la sociedad está correctamente ordenada, y esto sucede cuando las instituciones sociales más importantes se ordenan de forma que obtienen el mayor equilibrio neto de satisfacción, distribuido entre todos los individuos pertenecientes a ella. Así, el principio fundamental de justicia sería la maximización de la utilidad del colectivo, o sea, que el bienestar de una sociedad depende de la suma del bienestar de sus integrantes.

En los contratos que fueron la base para las primeras teorías sólidas sobre el mismo, las personas afectadas por él eran mayoría, comparadas con aquellas que se constituyeron en partes contratantes "oficiales". Estas personas pertenecían a una minoría, por lo que la diversidad no estaba presente y no había una justa distribución de derechos. Sólo hombres adultos y "ciudadanos" (lo cual estaba muy relacionado con la alta clase 
social y ese sexo), y organizaciones formadas por ellos, podían aspirar, por ejemplo, a las garantías legales de la época. Las/os demás, mujeres, menores o minorías étnicas, entre otros, vivían en esa sociedad y no figuraban como titulares de la misma para los derechos, pero sí para los deberes, pues eran fundamentales para el funcionamiento del sistema productivo, entre otros.

Hobbes (1984) defendió que, en estado político, la garantía de la no violencia del ser humano viene derivada de la coerción. Es el Leviatán, el Estado, la institución necesaria para resolver el problema humano de la convivencia y el orden social ya que, con un poder superior, los humanos pueden optar a convivir, algo que no conseguirían por sí mismos, beneficiándose así de la vida en sociedad.

Para Locke (1995), todas las personas son fundamentalmente iguales, algo a lo que otorgó carga moral al eliminar las subordinaciones entre las mismas siempre que formen parte del contrato. Pero, la línea de la teoría clásica consideraba que los seres humanos que podían formar parte del contrato eran hombres adultos y ciudadanos. Además, entendía la implantación de la ley como un modo de preservar y mejorar nuestra libertad, porque veía la vida en sociedad como un modo de proteger aquello que en el estado de naturaleza corre peligro, como es la paz o la propiedad. Así, sostenía que:

[...] la finalidad de la ley no es abolir o restringir, sino preservar y aumentar nuestra libertad. [...] Pues la libertad consiste en estar libre de la violencia de los otros, lo cual no puede alcanzarse donde no hay ley. (Locke, 1995, p. 95).

Por su parte, Kant (2006) basaba su idea de contrato en el beneficio mutuo entre las partes. Avanzó en la concepción del contrato social con un renovado concepto sobre la moral, con la creencia de que los seres humanos deben ser tratados siempre como fines y nunca como medios:

El hombre, como todo ser racional, existe como fin en sí mismo, no solamente como medio para el uso arbitrario de ésta o aquella voluntad, sino que debe considerarse en todas sus acciones... al mismo tiempo como un fin. (Kant, 2006, cap. 2).

A pesar de que abordó en su moral el problema de las personas dependientes, Kant argumentaba que las partes del contrato deben "aportar" en el sentido defendido por el beneficio mutuo, quedando al descubierto la problemática de las personas que no están capacitadas para contribuir.

Rousseau (1993) partió de la tesis que supone que todos los hombres nacen libres e iguales por naturaleza, y sostuvo que el pacto social convierte en iguales a los hombres por convención y derecho. Pero, como Locke, se refiere a los "hombres" que disfruten de independencia social, dejando nuevamente a todo el resto de población "fuera". Formuló en los siguientes términos su idea del pacto social: "Cada uno de nosotros pone en común su persona y todo su poder bajo la suprema dirección del beneficio general, 
recibiendo a cada miembro como parte indivisible del todo." (Rousseau, 1993, p. 47).

Contrastando con estos autores clásicos, las formas de contractualismo más contemporáneas son modelos que tienden más a la equidad o a la mutua aceptabilidad de todo tipo de personas, y no están tan centrados en el beneficio mutuo. Así, la idea principal de la teoría de Rawls (2002) es de que los principios de justicia son el resultado de un acuerdo original. El acuerdo sustituye a la noción tradicional de contrato, y a ese acuerdo llegarían personas libres y racionales interesadas en promover sus propios fines en una situación inicial de igualdad (posición original).

La teoría rawlsiana es más inclusiva que las tradicionales con respecto a personas de todo tipo, pero su concepto de "racionales" es problemático en relación a las personas con necesidades específicas y a los animales no humanos, debido a la presencia de la idea de beneficio mutuo en su teoría, ya que, al contrario de Nussbaum (2006), por ejemplo, descarta toda presunción de altruismo o benevolencia. Para Nussbaum, la forma correcta de fundamentar la igualdad moral no pasaría por ninguna supuesta igualdad de facultades, porque las partes del contrato no tendrían nunca igualdad en ese sentido.

Así, las personas afectadas por el mismo deben ser libres, iguales y no necesariamente independientes, ya que muchas de ellas no son autosuficientes, como las de corta y avanzada edad, las que tienen problemas psíquicos o físicos, o los animales no humanos. La defensa del altruismo frente al beneficio mutuo es clave para un funcionamiento contractual justo, básico para la cooperación social. En esta dirección, Sen (2010) argumenta que el contractualismo clásico estaba basado en la aplicación coactiva del acuerdo, mientras que el moderno lo estaría en la voluntad de todos los humanos, en lo pactado. Habría así dos grandes maneras de proponer el éxito de beneficios mutuos a través de la cooperación: contratos sociales o con normas sociales que evolucionan hacia la voluntariedad.

El estado de crisis en el que se encuentra el contrato en nuestros días es destacado por Santos (2007), ya que éste fue y es víctima de un falseamiento, debido al aumento en las restricciones de los derechos de una parte de los contratantes. Señala al respecto dos conceptos clave: post-contractualismo, que se refiere a que grupos e intereses incluidos hasta ahora, son excluidos; precontractualismo, que se refiere al bloqueo de entrada a grupos que antes tenían la expectativa de hacerlo. Estos dos conceptos están ligados a la contemporaneidad por medio del consenso liberal, que se sostiene sobre cuatro pilares (Santos, 2002): 1) Consenso económico neoliberal; 2) Consenso del Estado débil; 3) Consenso democrático liberal (democracia "formal" y no real); 4) Consenso del primado del derecho y de los tribunales.

Esos desequilibrios y la falta de coherencia democrática provocadas por las élites conducen a la "desocialización de la economía", entendida como la desregulación de las transacciones económicas en beneficio del capital, dejando sin amparo a las personas más desfavorecidas.

Por razones como las analizadas, se puede pensar que la cuestionable "paz social", fruto tantas veces de contratos no legítimos en todo el mundo, 
es más parecida a un estado de forzada calma que a una situación de natural tranquilidad derivada de la justicia en ellos. Es, por tanto, una paz artificial, al estilo de la "Paz Romana" (pax romana), que fue el período de tensiones y guerras impuesto por el Imperio Romano a los pueblos que estaban bajo su dominio. Después de la caída del Muro de Berlín, y con el comunismo derrotado como bloque, el vencedor reclamó sus derechos a través de una paz estable, que no es otra cosa que la tranquilidad derivada de la imposición de sus postulados, aunque la propia paz sea la sacrificada. Y es la idea de contrato social, como en el pasado, la utilizada nuevamente para legitimar las asimetrías de poder propias de nuestra época, la encargada de diseñar la pax capitalis.

En muchos de los denominados países democráticos, donde la crisis económica está azotando fuerte, sobre todo a los sectores sociales que poco tienen que ver con su origen, incluso la paz social impuesta está corriendo serio peligro. Asistimos en 2011 a fenómenos de importancia planetaria, tales como la Primavera Árabe, el 15M u Occupy Wall Street, que muestran claramente que se está rompiendo, también, el Contrato Social impuesto, la "pax" del imperio.

Muchos de estos movimientos sociales tienen en el anticapitalismo un nexo común, y están poniendo a prueba la estabilidad hegemónica con sus acciones, postulados e iniciativas, con la participación realmente pacífica como señal diferenciadora. Pero las manifestaciones y concentraciones legales son reprimidas con contundencia por las fuerzas de seguridad de los distintos países, porque tal y como defendía Arendt (1998), la violencia $y$ el terror son fundamentales en el sistema para mantener el statu quo. Cumplen la doble función de demostración de la supuesta verdad, y de castigo frente al desvío de las normas y leyes de la propaganda.

Necesitamos salir de la artificial pax capitalis construyendo otra distinta, auténtica, que sea la hija legítima de la justicia social. Distintas sociedades en el mundo reclaman que todas las figuras humanas afectadas por los contratos sociales tienen que estar incluidas, en todas sus variedades, y no sólo las de la monocultura del poder. Más allá del beneficio mutuo, el altruismo y la búsqueda del bien y justicia para todas las personas (dependientes o no) y animales no humanos deben tornarse en nueva pieza clave de un contrato distinto, en el que la justicia social sea objetivo y herramienta al mismo tiempo, para que el contrato tenga legitimidad y duración.

\section{Una educación que forme para conseguir acuerdos en red y no contratos parciales}

Todos los autores clásicos del contrato dieron una importancia decisiva a la educación a la hora de cambiar las cosas en lo social. Hobbes (1984) defendía que el ser humano vive bien en sociedad gracias a la llegada de la educación y no por naturaleza. Locke (1995) partió de la idea de que no hay principios innatos en la mente y que son la educación, la razón, el 
aprendizaje o la política las que construyen los principios. Kant (2006) puso en las manos de la educación la labor de crear y alimentar valores como la bondad, la amistad, la belleza, la solidaridad, que son, según él, cuestiones que tienen que ser aprendidas y que no vienen dadas. Rousseau (1993) consideraba a la educación como el camino idóneo para formar ciudadanía libre consciente de sus derechos y deberes en el nuevo mundo que estaba por nacer.

En las teorías clásicas de estos autores, existen elementos morales que están levemente presentes. Pero la moralidad es una cuestión que puede jugar un papel decisivo a la hora de defender modelos educativos inclusivos y basados en el altruismo y la solidaridad, a través de un camino alternativo al del dominio utilitarista de la pax capitalis. En modelos contractuales contemporáneos, como el propuesto por Nussbaum, la carga moral es mayor y por lo tanto se apoya más en asuntos derivados de los derechos naturales, es decir, prepolíticos y no contractuales. Su teoría "utiliza una concepción política de la persona como un animal social y político, cuyo bien es irreductiblemente social y que comparte fines complejos con otras personas en muchos niveles" (Nussbaum, 2006, p. 166). Así, el bien de las demás personas sería también mi propio bien. Siguiendo esta dirección propuesta por la autora, es posible hacer el ejercicio de reflexionar sobre cómo podría ser el Contrato Social hoy en día según este modelo y con respecto a la educación:

1. El cumplimiento de unas circunstancias de la justicia: según las cuales las partes asumen el contrato porque les interesa a todas. Pero es fundamental saber por qué asumen las partes el contrato, si es por voluntad propia, necesidad o imposición. En los contextos educativos, como en el social, el equilibrio de poder entre las partes no suele ser una realidad, y son mayoría los casos en que, por ejemplo, el alumnado y familias no disponen de espacios para expresarse o tomar decisiones, y el miedo a la represalias es con frecuencia suficiente para que las partes dominadas no acaben con esa paz impuesta.

2. Partes libres, iguales e independientes: alumnado y familias (entre otros) son dependientes de las partes fuertes del contrato, las que organizan políticas educativas, editoriales o la dirección de los centros. Así, no disfrutan de completa libertad e igualdad necesarias para su inclusión en condiciones equitativas dentro del mismo, por su clara dependencia.

3. El beneficio mutuo como finalidad de la cooperación social: el altruismo y la búsqueda del bien y justicia para las demás personas (dependientes o independientes) son posturas que incluyen este nuevo tipo de contractualismo, y que fueron tradicionalmente descartadas por las/os filósofas/os como elemento central del Contrato Social. La cuestión primaria aquí es la pertenencia a la condición humana, no tanto la capacidad de contribuir socialmente. Así, estudiantes y familias, aunque tuvieron menos posibilidades de contribuir en ese contrato educativo, deberían ser parte integrante y protagonista del mismo, bajo este tipo de parámetros.

Los sistemas educativos son una parte esencial para el establecimiento de los contratos sociales, y además podemos visualizarlos como contratos 
en sí mismos, compuestos de partes con intereses enfrentados en muchos momentos.

Para poder llegar al acuerdo que da paso al contrato, es interesante saber a qué tipo de libertades renuncia cada parte para conseguir la deseada armonía en la convivencia. El contrato puede estar alterado o no funcionar bien porque haya una descompensación de libertad, igualdad e independencia entre las partes que lo componen. Con esta situación corremos el riesgo de que, por falta de cumplimiento del contrato por una de las partes, las otras estén en constante tensión. La desconexión de los estudiantes con los contenidos, procedimientos y actitudes formales y tradicionales, las muestras de problemas de convivencia en los centros educativos, o la visión de que estos son más un requisito para satisfacer demandas sociales que lugares donde fluya un conocimiento vivo, interactivo y cambiante, pueden ser muestras de que el contrato no está equilibrado y de que hay problemas de convivencia dentro de él, que existe una imposición de la paz.

Este modelo desequilibrado entre las fuerzas diseña así un contrato falseado, de pseudoestado de naturaleza. Es por eso que, atendiendo a exigencias democráticas y de justicia social, se hace necesario un pacto que sea más equitativo, justo y válido para las partes que lo componen, y sobre todo para aquellas más desfavorecidas en él.

Conflictos como los señalados, así como la constante percepción social de que las cosas no funcionan como deberían dentro de numerosas esferas educativas a lo largo del mundo, brindan información sobre esas situaciones que necesita ser analizada. Siguiendo características básicas de la teoría del contrato, mediante éste deberíamos poder garantizar en buena medida la paz y armonía dentro de las escuelas e instituciones de las que dependen, para poder cohabitar con la seguridad de poder llevar una vida acorde con las necesidades de todas las comunidades educativas.

La violencia, la falta de redistribución en los recursos, la exclusión educativa o la competitividad son sólo algunos ejemplos de un estado de naturaleza encubierto (en el peor de los sentidos clásicos del concepto) que se da con demasiada frecuencia. Con enormes y crecientes situaciones de injusticia y falta de equidad dentro y fuera de las aulas, la estabilidad del Contrato Social que abriga esas condiciones debería ser puesta en tela de juicio, ya que sin justicia no puede haber paz social, y sin paz no hay motivos para tener que cumplir el contrato. Paz a la que, curiosamente, deberíamos llegar mediante el conflicto político, o dicho de otro modo, a través de la politización de las prácticas socioeducativas, cuestionando la pretendida asepsia y neutralidad de la pax capitalis, esa otra paz impuesta. Además de esto, podríamos plantear en este contexto que, algunos elementos propios del estado de naturaleza como los derechos prepolíticos, puedan ser interesantes para encontrar esa otra paz social. Así, recurrir a derechos derivados de la pertenencia a la especie humana, según los cuales podríamos tener garantizadas una serie de capacidades básicas para ser felices y desarrollarnos (Nussbaum, 2006) sería una radical forma de inclusión social y educativa. 
Para alcanzar ese estado es necesario intentar avanzar apostando por formación humana, ética, solidaria, actual, de calidad, y sobre todo crítica, y que recoja las necesidades del alumnado, de modo que haya un acuerdo en el contrato por aceptación de las condiciones y no por coerción. Este último punto es necesario para evitar la desconexión del estudiantado de lo que sucede dentro de las escuelas y las aulas, para lo cual necesita gozar de autonomía y cuotas de participación efectiva dentro de los diferentes consejos y asambleas escolares, para legitimar así un Contrato Social dentro de los muros de los centros que es constantemente debilitado por la ausencia de equidad participativa entre los diferentes colectivos.

Apostando por ese tipo de educación, ésta podría obtener sus raíces epistemológicas de fuentes diversas, de forma que se ejercite una filosofía inclusiva de los saberes y que tenga sus principios fundamentados en modelos contractuales fuertemente basados en la solidaridad y la benevolencia, para lo cual es necesario volver a afrontar las cuestiones morales con valentía a la hora de hacer frente a las lógicas utilitaristas.

En este sentido, Santos (2007) sostiene que la enorme diversidad del mundo no es atendida por su diversidad epistemológica, que está por ser construida a través de lo que denomina Ecología de Saberes. Es fundamental en ella el reconocimiento de la pluralidad de conocimientos heterogéneos para construir una nueva forma de percibir el mundo, a través por ejemplo, del estudio de las injusticias y la historia de la dominación, así como de posibles caminos de comprensión y colaboración para su solución.

Una educación comprometida con otra forma de acordar, de pactar entre seres humanos para convivir, tiene que tener estos elementos muy en cuenta. El respeto y valoración de diferentes formas de ser, conocer y aprender es fundamental para una paz social verdadera y no impuesta, una paz basada en la justicia epistemológica.

Para conseguir objetivos tan ambiciosos debe haber una respuesta educativa a los desafíos que presenta la globalización capitalista. Una educación entendida desde la radicalidad democrática puede tener como soporte la perspectiva de red, con características constituyentes como la participación real de toda la comunidad educativa, la multiplicidad epistemológica, la inclusión educativa, la horizontalidad y la participación democrática, la solidaridad, el altruismo, la bondad, etc., y donde la justicia curricular sea protagonista (Torres Santomé, 2011, p. 11):

El resultado de analizar el curriculum que se diseña, pone en acción, evalúa e investiga tomando en consideración el grado en el que todo lo que se decide y hace en las aulas es respetuoso y atiende a la necesidades y urgencias de todos los colectivos sociales; les ayuda a verse, analizarse, comprenderse y juzgarse en cuanto personas éticas, solidarias, colaborativas y corresponsables de un proyecto amplio de intervención sociopolítica destinado a construir un mundo más humano, justo y democrático.

Esa educación debe beber de las experiencias sociales para aprender nuevos modelos de organización, más acordes con el tiempo en el que tiene 
que intervenir y con los objetivos deseados para crear una vía alternativa a la pax capitalis. Desde la perspectiva de la complejidad, Escobar (2004, p. 650) señaló una serie de características sobre los movimientos sociales contemporáneos y su forma de organizarse en malla o red, que pueden ser muy pertinentes para estas nuevas formas de organización educativa: la malla no puede ser jerárquica, es autoorganizada y maleable; existe un doble desafío: defensa de lo local para su expresión y la reestructuración de los mundos locales por la cultura global; el carácter político de la malla apoya buena parte de su peso en las intersecciones de las identidades diversas conformantes; los resultados de las prácticas de las mallas pueden ser encuadrados como la creación de configuraciones alternativas de cultura, economía, naturaleza e identidad, que no se subordinan a los principios organizativos neoliberales y modernos.

Por la propia idiosincrasia estructural de las redes, éstas necesitan de un tejido conectivo no sólo amplio, sino infinito, no sólo equilibrado a nivel participativo, sino horizontal, no sólo con presencia parcial de sus nodos, sino global y constante. El tejido social en red requiere de conexiones y coordinación para funcionar, y dentro de éste se debe encuadrar la educación como elemento catalizador de las mismas. Puede ser una senda a seguir por la propia educación para caminar con coherencia en las democracias participativas y la justicia social. Para ello, la escuela debe salir y tejer alianzas y conexiones, compartiendo el trabajo de educar con un conjunto de personas y organizaciones también presentes en la vida del alumnado, tales como ONGs, cooperativas, sindicatos, bibliotecas, asociaciones ciudadanas, etc., al mismo tiempo que dentro de ella se elaboran proyectos necesarios para el resto del tejido social.

La red implica que lo que sucede en un nodo afecta a todo el conjunto de la misma, de forma que la actuación coordinada es imprescindible a la hora de intervenir en ella. En un mundo cada vez más complejo y en el que la estanqueidad tanto epistemológica como procedimental está siendo cuestionada, la defensa de las relaciones complejas entre saberes, personas y/o instituciones parece una expresión más del tejido en red. En él, el concepto de hibridez (Bhabha, 2011), es decir, lo referido a lo que no puede ser situado en categorías sociales y que se esconde de las mismas desde la asunción de su complejidad, desde la diferencia, se postula como esencial.

Diferentes nodos en la sociedad o en la educación, o lo que es lo mismo, diferentes personas, grupos o instituciones podrían explotar su complejidad interna, valorándola en lugar de renunciar a ella. Es por esto que, para este modelo de educación en red, necesitamos alumnado que forme y profesorado que aprenda, familias que enseñen y educadoras/es que amen y cuiden, políticas/os que eduquen y educadoras/es que politicen...

La organización de la educación y el conocimiento en red, y la importancia de la conexión de creencias o informaciones por medio de nodos que actúan como unión, mezcla y reelaboración de todas ellas, es una forma de organización propia del avance del conocimiento y del tipo de sociedad que está siendo construida, de forma que es adoptada tanto por aquel que es denominado alternativo como por el hegemónico, por lo que surge una 
nueva forma de orden global, un imperio (Negri; Hardt, 2004), una red de poder que contribuye con otro tipo de soberanía. A la vez, la educación tiene en esta vía alternativa de conocer y de organizarse, una herramienta indispensable tanto para su coherencia interna como para su colaboración en la construcción de nuevos pactos sociales horizontales.

Cuestiones como las planteadas indican la necesidad de experimentar, intentar o apostar por otra forma de relacionarnos y de percibir el mundo. Pensar, investigar y educar en red exige, entre otras cosas, la posibilidad de probar múltiples y diversos caminos, la inexistencia de jerarquías o la vía de la multidisciplinariedad (Alves, 2001). Desde esta diferente forma de entender el conocimiento y la educación, estaríamos cumpliendo con dos requisitos:

1. El de la justicia epistemológica: la complejidad del mundo sólo puede aspirar a ser percibida por la diversidad y trabajo conjunto de los saberes de la humanidad, asumiendo su interconexión pasada y presente, su mutua dependencia y su necesaria independencia de la creación a posteriori de las jerarquías de poder entre las personas y los grupos humanos. Por lo tanto, el rigor y la seriedad a la hora de educar demandan un tratamiento serio de las diferentes realidades a través de conocimientos diversos.

2. El de la justicia social: cuando hablamos en serio de sociedades democráticas no podemos permitir su definición y comprensión a través de una educación jerarquizada y no participativa. Una educación que aspire a ser coherente con un sistema realmente democrático en el que esté inserta, no puede tejer un camino con métodos unidireccionales y homogéneos; no puede ser democrática, en definitiva, sin la negociación, la comprensión y el diálogo. La justicia social y la democracia necesitan para su buen funcionamiento de formas de educar acordes con lo que demandan intrínsecamente.

\section{Conclusiones}

Para poder entender mejor la contemporaneidad es necesario romper la barrera que separa las herramientas conceptuales del Contrato Social y del Estado de Naturaleza. Vivimos en sociedades crecientemente complejas y en las que las explicaciones dicotómicas habitualmente fracasan, por lo que asumir el reto de entenderlas desde la intersección de perspectivas se antoja no sólo como un ejercicio de responsabilidad democrática, sino también como un requisito indispensable para cumplir esta tarea con rigor.

Contextos sociales temporalmente estructurados en los que reina el caos, y supuestos estados de naturaleza donde es posible encontrar una cierta armonía, conforman muchas de las realidades de nuestro mundo. Denominamos como pacíficas sociedades enfermas desde posiciones de radicalidad democrática por tener una estructuración social y legislativa ya instalada, al mismo tiempo que consideramos enfermas experiencias sociales democráticamente satisfactorias por el hecho de no contar con 
ella. La actual crisis capitalista nos ofrece la posibilidad de penetrar en estas contradicciones para hacerles frente.

Para llevar a cabo esta tarea de aprendizaje, es necesario contribuir desde la educación en el juicio crítico hacia esa forma de entender el mundo, utilizando para ello la idea de red, que además de ser un objetivo a perseguir como forma de estructuración socioeducativa, puede ser también un camino de expresión de la propia calidad democrática.

\section{Bibliografía}

ALVES, N. Decifrando o pergaminho: o cotidiano das escolas nas lógicas das redes cotidianas. In: OLIVEIRA, I. B.; ALVES, N. (Org.) Pesquisa no/ do cotidiano das escolas: sobre redes de saberes. Rio de Janeiro: DP\&A, 2001.

ARENDT, H. Los orígenes del totalitarismo. Madrid: Taurus, 1998.

BHABHA, H. O bazar global e o clube dos cavalheiros ingleses: o entrelugar das culturas. Rio de Janeiro: Rocco, 2011.

CASTRO GARCÍA, M. Violencia escolar y victimismo general. Rebelión. Disponible en: <http://www.rebelion.org/noticia.php?id=39688>. Acceso el: 7 mayo. 2014.

ESCOBAR, A. Atores, redes e novos produtores de conhecimento: os movimentos sociais e a transição paradigmática nas ciências. In: SANTOS, B. de S. Conhecimento prudente para uma vida decente. São Paulo: Cortez, 2004.

HOBBES, T. Leviatan, o la materia, forma y poder de la República Eclesiástica y Civil. Madrid: Sarpe, 1984.

HUME, D. Tratado de la naturaleza humana. Madrid: Tecnos, 1988.

KANT, I. Fundamentación de la metafísica de las costumbres. Madrid: Tecnos, 2006.

LOCKE, J. Segundo tratado sobre el gobierno civil. Barcelona: Altaya, 1995.

NEGRI, T.; HARDT, M. Prefacio: vida en común: multitud. guerra y democracia en la era del imperio. Madrid: Debate, 2004. 464 p.

NUSSBAUM, M. Las fronteras de la justicia. Barcelona: Paidós, 2006. $448 \mathrm{p}$. 
OLIVERES, A. Se da a la banca 92 veces lo que se pide para erradicar el hambre en el mundo. El Correo. Disponible en: <http://www. elcorreo.com/vizcaya/v/20120521/guipuzcoa/arcadi-olivares-bancaveces-20120521.html>. Acceso el: 7 de mayo. 2014.

RAWLS, J. La justicia como equidad. Madrid: Tecnos, 2002. 288 p.

ROUSSEAU, J. J. Contrato social. Madrid: Espasa Calpe, 1993. 170 p.

SANTOS, B. de S. Reinventar a democracia. 2. ed. Lisboa: Gradiva, 2002. $75 p$.

SANTOS, B. de S. Para além do pensamento abissal: das linhas globais a uma ecologia de saberes. Revista Crítica de Ciências Sociais, Coimbra, n. 78, p. 3-46, out. 2007.

SEN, A. La idea de la justicia. Madrid: Taurus, 2010. 470 p.

TORRES SANTOMÉ, J. La justicia curricular: el caballo de Troya de la cultura escolar. Madrid: Morata, 2011. 312 p.

Carlos Riádigos Mosquera é doutor em Educação na área de Currículo (2014) pela Universidade de A Coruña (UDC), Galiza, Espanha. É pesquisador na área de Educação em Teoria Geral de Planejamento e Desenvolvimento Curricular, com trabalho específico em justiça social, novas tecnologias/ redes sociais, movimentos sociais, e análise de material curricular na Faculdade de Educação da Universidade de A Coruña (UDC), Espanha, e na Faculdade de Educação da Universidade do Estado do Rio de Janeiro (UERJ), Rio de Janeiro, Brasil.

carlos.riadigos.mosquera@udc.es

Recebido em 12 de maio de 2014.

Aprovado em 14 de agosto de 2014. 